\title{
Chapter 4 \\ The Quality of Student Perception Questionnaires: A Systematic Review
}

\author{
Hannah Bijlsma
}

\begin{abstract}
Student perceptions of teaching are promising for measuring the quality of teaching in primary and secondary education. However, generating valid and reliable measurements when using a student perception questionnaire (SPQ) is not self-evident. Many authors have pointed to issues that need to be taken into account when developing, selecting, and using an SPQ in order to generate valid and reliable scores. In this study, 22 SPQs that met the inclusion criteria used in the literature search were systematically evaluated by two reviewers. The reviewers were most positive about the theoretical basis of the SPQs and about the quality of the SPQ materials. According to their evaluation, most SPQs also had acceptable reliability and construct validity. However, norm information about the quality rating measures was often lacking and few sampling specifications were provided. Information about the features of the SPQs, if available, was also often not presented in an accessible way by the instrument developers (e.g., in a user manual), making it difficult for potential SPQ users to obtain an overview of the qualities of available SPQs in order to decide which SPQs best fit their own context and intended use. It is suggested to create an international database of SPQs and to develop a standardized evaluation framework to evaluate the SPQ qualities in order to provide potential users with the information they need to make a well-informed choice of an SPQ.
\end{abstract}

Keywords Student perception questionnaires $\cdot$ Teaching quality $\cdot$ Systematic review

\section{Introduction}

Student perceptions of teaching are promising as a way to measure the quality of teaching in primary and secondary education (Ferguson, 2012; Ferguson \& Danielson, 2014; Schulz et al., 2014; van der Scheer et al., 2018). The scores provided by students with regard to their teachers' teaching can be used for research

\footnotetext{
H. Bijlsma ( $\varangle)$

Section of Teacher Professionalization, University of Twente,

Enschede, the Netherlands

e-mail: h.j.e.bijlsma@utwente.nl 
and accountability purposes, for example, or for teacher professional development (Timperley et al., 2007). A student perception questionnaire (SPQ) is often used for collecting student perceptions of teaching quality, and usually consists of a set of items about the quality of teaching that students have to respond to using a numeric scale. An SPQ also involves the information and activities required to use the instrument as intended. Therefore, ideally, an SPQ also includes a user manual, scoring rules, and sampling specifications (for example, specifications regarding the subject of the lesson). Although the use of SPQs is not new, several studies (Bijlsma et al., under review; Lüdtke et al., 2006; van der Scheer et al., 2018; Wallace et al., 2016) have recently generated renewed interest in reliability and validity issues surrounding SPQs and other teacher evaluation approaches, such as classroom observation systems (Bell et al., 2018; Dobbelaer, 2019).

Generating valid and reliable scores using an SPQ is not guaranteed. Many authors (e.g., Bijlsma et al., under review; van der Lans \& Maulana, 2018; and Chap. 7 by Göllner et al., in this volume) have pointed to issues that need to be taken into account when developing and/or using an SPQ in order to generate valid and reliable scores. These include issues regarding the theoretical basis of the items and the constructs that the SPQ aims to measure. However, these issues are often not (fully) addressed by SPQ users or developers, bringing the reliability and validity of the student scores into question. Moreover, there is no overview of the student perception questionnaires available for use in primary and secondary education that identifies what their psychometric characteristics are and what teaching quality constructs they aim to measure. Therefore, in this study, a systematic review was conducted of SPQs in primary and secondary education. The SPQs found were reviewed, based on an evaluation framework developed for this study. An overview with general information about the SPQs and the results of the evaluation and an overview with the constructs measured by the SPQs are presented. The overviews contribute to an increased awareness of the complexity of SPQs by developers and users, and to the deliberate design and use of SPQs. Note that in this chapter, a clear or standard definition of teaching quality is not presented, because consensus about its conceptualization or definition across SPQs is minimal (Cohen \& Goldhaber, 2016).

\section{The Evaluation Framework}

A selection of SPQs was reviewed using an evaluation framework (available in Dutch) consisting of seven standards: the theoretical basis of the questionnaire, the quality of the questionnaire, the quality of the manual, norms, reliability, construct validity, and criterion validity. The standards in the framework were drawn from two strands of literature: the literature on SPQs and the literature on testing and performance 
assessment (the COTAN evaluation standards for test quality, Evers et al., 2010 ${ }^{1}$ ). The evaluation framework and the underlying theory are outlined in the following paragraphs. Additionally, SPQ assessment purposes are distinguished and discussed.

\subsection{Evaluation Standard 1-The Theoretical Basis of the Questionnaire}

Each SPQ in this review includes a scoring format or tool consisting of items that are scored on a rating scale. In most SPQs, several items can form a construct ${ }^{2}$ (Marsh, 2007), an aspect of teaching quality as perceived by students (Maulana \& HelmsLorenz, 2016). All SPQs measure the quality of teaching; however, they can focus on different constructs that are perceived by students. Based on several meta-analyses related to effective teaching (Praetorius et al., 2018; Bell et al., 2018; Creemers, 1994; Pianta \& Hamre, 2006; Sammons et al., 1995), nine constructs that are known to be effective for student learning are distinguished in this study: a safe and stimulating classroom climate, classroom management, the involvement and motivation of students, explanation of subject matter, the quality of subject-matter representation, cognitive activation, assessment for learning, differentiated instruction, and teaching learning strategies and student self-regulation. The constructs in SPQs can be derived from different theories, research, or standards, but all should have a solid scientific basis (American Educational Research Association [AERA] et al., 1999) and the items should cover the theoretical constructs (Evers et al., 2010). Although the theoretical basis of the questionnaires was evaluated in this review, it was not feasible to evaluate the quality of the research underlying the questionnaire, as well.

\subsection{Evaluation Standard 2-Quality of the Questionnaires}

To evaluate the quality of the questionnaires (this corresponds to "material" in general psychological tests), the item design of the SPQ is considered and it is determined whether the scoring system and procedure are standardized. The items on the SPQ can be subject-specific (e.g., designed to capture the quality of mathematics teaching) or generic (items that can be used across subjects), and can focus on teachers' actions, students' actions, or both (Bell et al., 2018). The number of items included in the

\footnotetext{
${ }^{1}$ The COTAN evaluation standards are used by the Dutch Committee on Tests and Testing (COTAN) to evaluate the quality of psychological tests available in the Netherlands. COTAN has audited over 750 tests published for professional use.

${ }^{2}$ Others have used terms such as dimension, scale, or pattern to refer to what I am calling "construct," but in my opinion such terms do not capture well the conceptual link with the aspects of teaching quality perceived by the student.
} 
scoring tools can differ as well as the response categories in the rating scale. Strong (2011) pointed out that a large number of items can be problematic for students because "there is an upper limit of a rater's ability to match his or her responses to a given set of stimuli" (the channel capacity; Strong, 2011, p. 88). Although utilizing a small number of items may reduce students' cognitive load and be adequate for evaluating teaching quality, more items enable providing richer feedback to teachers on their strengths and weaknesses, which is needed for improvement (Marzano, 2012).

\subsection{Evaluation Standard 3-The Quality of the Manual}

A description of the scoring tools should enable potential users to judge whether an SPQ is suitable for their purposes and should therefore include a description of the constructs the SPQ aims to measure, the type of use for which the SPQ has been developed and who/what can be observed by using the SPQ (Evers et al., 2010).

\subsection{Evaluation Standard 4-Norms}

Numeric ratings usually result in a raw score, which is partly determined by the characteristics of the SPQ. The norms evaluation standard evaluates whether the SPQ provides a meaningful interpretation of its results (Evers et al., 2010). Two ways of "scaling" or categorizing can be used to interpret the raw scores (American Educational Research Association (AERA), (APA), and (NCME), 1999). First, a set of scaled norms may be derived from the distribution of the raw scores of a reference group. This is called norm-referenced interpretation (Drenth \& Sijtsma, 2006; Bechger et al., 2009). Second, standards may be derived from a domain or subject matter to be mastered or from the results of empirical validity research: the domain-referenced interpretation and the criterion-referenced interpretation, respectively (Berk, 1986; Vos \& Knuver, 2000). The raw scores are given meaning by providing norms or standards and it makes the SPQ more user-friendly.

\subsection{Evaluation Standard 5-Reliability}

Providing reliability evidence is primarily the responsibility of SPQ developers since prospective users need this information to make an informed choice among alternative instruments or other measurement approaches and prospective users will generally be unable to conduct reliability studies prior to the operational use of an SPQ (AERA et al., 1999). In this evaluation, the assessment purpose was taken into account. A higher reliability coefficient (or a similar measure) is more critical for 
high-stakes decisions (e.g., tenure decisions) than for low-stakes decisions such as teacher professional development activities. The quality of the research was also taken into account (as suggested by Evers et al., 2010), namely, whether the (analysis) procedures followed were correct, whether the research had been conducted in the target group of the SPQ (e.g., an SPQ designed for primary education should be investigated in primary education) and whether developers provided enough information to thoroughly judge the reliability of the SPQ scores. Various types of reliability measurements can be used, such as parallel-form and split-half reliability, reliability on the basis of inter-item covariance, test-retest reliability, interrater reliability, generalization theory, and structural equation models. Other methods for reliability testing are Guttman's lambda2 (Guttman, 1945) and the greatest lower bound (glb; ten Berge \& Socan, 2004). For a more detailed description of Generalizability Theory (as well as Classical Test Theory and Item Response Theory), see Chap. 2 by Bijlsma et al., in this volume.

\subsection{Evaluation Standard 6-Construct Validity}

Validity reflects the extent to which an SPQ fulfills its purpose (the measurement of a specific construct; Drenth \& Sijtsma, 2006). This shows whether the instrument is useful or not. Validity is "a matter of degree rather than an all-or-none property and validation is an unending process" (Nunnally, 1967, p. 75). Several methods can be used to support construct validity such as research on the (uni)dimensionality of the items (explanatory or confirmatory factor analyses), the quality of the items and the fit of the items to a model (e.g., IRT model, see Chap. 2 by Bijlsma et al., in this volume), and the correlations between relevant scales.

\subsection{Evaluation Standard 7-Criterion Validity}

To demonstrate the relationship of variables (e.g., do the SPQ scores for teachers' teaching quality relate to student achievement), criterion validity (also called predictive validity) can be investigated. Some SPQs are developed specifically for the purpose of investigating criterion validity. In addition, aspects of validity could also be captured through interviews with the students, which could relate to the content and factual accuracy of their understanding of the items. But this type of validity research is not always conducted. 


\subsection{Possible SPQ Assessment Purposes}

The evaluation standards described above are based on the circumstances of psychological testing procedures and not, for example, on their use as a pure feedback instrument via reporting student perceptions of teaching. The necessity of meeting each standard is related to the assessment purpose of the SPQ. For example, norms are not necessarily needed when you use the student perception scores as feedback to teachers, nor are construct and criterion validity (Kane, 2006). In the context of this chapter, I distinguish four SPQ assessment purposes (Mislevy, 2013; Bell, 2019): assessment for research practice (e.g., for measuring intervention effects), assessment as a feedback loop (e.g., for improvement at the teacher level [teaching quality] or school level), assessment as an evidentiary argument (e.g., to develop claims that are supported by measurements for personnel decisions), and assessment as a measurement (e.g., to specify and test assessment models as a way to work toward models that enable representation of real-world resources). In the results section, I overview which SPQs seem suitable for which assessment purpose.

\section{Method}

Before searching for SPQs, a review protocol was developed in collaboration with an information specialist. This protocol included the aim of the review, the research questions, the inclusion and exclusion criteria, and the search strategy.

\subsection{Inclusion and Exclusion Criteria for Questionnaires}

It specifies the characteristics of populations, interventions, contexts, and outcomes: Population: The SPQs were designed for use in primary and secondary education.

Intervention: The SPQs measure teaching quality. Aspects of learning climate and classroom climate were included as well as the extent to which students are involved in their lessons.

Context: The SPQs were designed for teacher-oriented lessons, such as mathematics, language, or reading.

Outcomes of interest: SPQs were only included if research had been done on the psychometric quality of the instrument. No exclusions were made based on the methodology of the study.

Other criteria for inclusion were forms of publication, language, and time period (Littell et al., 2008).

Forms of publications: To deal with publication bias, only peer-reviewed publications, dissertations, and unpublished articles were included. 
Language: No criteria were set based on the country where the instrument was developed. However, for practical reasons, only questionnaires published in Dutch and English were included.

Time period: Only questionnaires developed between 1970 and 2016 were included. SPQs developed earlier than 1970 would be very outdated and inappropriate for the current educational context, while 2016 was the year in which the research project took place.

\subsection{Search Strategy}

Littell et al. (2008) described a procedure to efficiently plan a systematic literature review. The steps of this procedure are: searching in bibliographic and scientific databases, using terms and strings; searching for sources of unpublished articles and dissertations, and asking for personal contacts. Based on the experiences of fellow researchers, the step of "hand searching" was not conducted, because it turned out that nothing relevant was found that way (Dobbelaer et al., 2015).

Following this procedure, first, six databases were searched (ERIC, PsycInfo, Web of Science, ProQuest, Scopus, and Narcis ${ }^{3}$ ) with the last search conducted in April 2016. The search terms included: evaluation, perception, student, teacher, education, school, and psychometric. Synonyms for each individual concept were combined with the Boolean operator $O R$ and all the different concept lists were combined using the Boolean operator AND. For Narcis, however, the same terms translated to Dutch were used for the search. The search terms are presented in the Appendix. All searches were run in all the databases in everything (title, abstracts, keywords) except full text. Backward-snowballing (reviewing the reference list of identified articles) resulted in more relevant SPQ publications and grey literature (unpublished articles and dissertations). The contacted field experts were all researchers conducting research into teaching evaluation, or had developed or used an SPQ in their research. A total of 92 researchers from 13 different countries were contacted for the purpose of both a systematic review of classroom observation systems (Dobbelaer, 2019) and for the current study. They were asked to name SPQ that met the inclusion criteria.

For the systematic review, the PRISMA reporting guidelines were followed (Liberati et al., 2009; Moher et al., 2009). A total of 1.544 publications were identified. After screening abstracts and titles, to check whether the articles were specifically about newly developed SPQs and not (for example about research done with an already available SPQ), 290 articles remained. Duplicates (56) were then removed and an additional 160 articles were removed after scanning the texts and reading the abstracts and titles more closely. 74 publications were then selected for full-text review. As a result of the full-text review, 49 additional publications were omitted based on the inclusion/exclusion criteria. Other publications, in which research had been done with the instrument, were read as well, to address practicality and usability

\footnotetext{
${ }^{3}$ Dutch database for scientific research.
} 
issues or-if available-interrater reliability. These were in total 25 questionnaires. The whole search was documented, using Refworks and Excel.

During the evaluation phase of this study, three questionnaires were determined to be not possible to evaluate. The Science-Technology Learning Environment Questionnaire (STLEQ) could not be evaluated because it did not meet the inclusion criterion of context. Comenius was the second questionnaire that could not be evaluated. This was due to language difficulties, which were not noticed during the search. The questionnaire was developed in Serbian and English, but the user guide and all other available sources were only available in Serbian. After contact with the developer, the decision was made not to evaluate the questionnaire. Lastly, the Learning Environment Inventory (LEI) was too out-of-date. The research done with the questionnaire was carried out in 1982, but it was originally developed in 1967. Both evaluators concluded that the questionnaire was too outdated, so it was excluded from the list. The elimination of these three questionnaires left a total of 22 questionnaires that were evaluated. Figure 1 shows the full flowchart of the PRISMA guidelines.

\subsection{Description of the $S P Q$}

A range of sources provided information about the SPQs: user manuals, manuals for SPQ use in research projects, peer-reviewed publications, dissertations, grey literature, websites, and personal contact with the authors. All relevant information was described in an overview for each SPQ, which included information on the general characteristics of the SPQ and the results of the evaluation. Additionally, the SPQ assessment purposes were analyzed and presented together with the descriptives for the SPQs.

\subsection{Evaluation Procedure}

The SPQs were reviewed based on the evaluation framework described above. After instruction in the use of the evaluation framework, two reviewers independently evaluated two SPQs. Based on the results, the two reviewers clarified all uncertainties and, where necessary, refined the evaluation framework. Next, two strongly differing questionnaires (in terms of development date, content, and intended use) were evaluated by both reviewers. The interrater reliability was then 0.87 (Kappa). Because this is considered high enough interrater reliability, the two reviewers independently evaluated all the remaining SPQs. After evaluating all SPQs, the scores were discussed by the two reviewers to come to an agreement about the final judgment. 


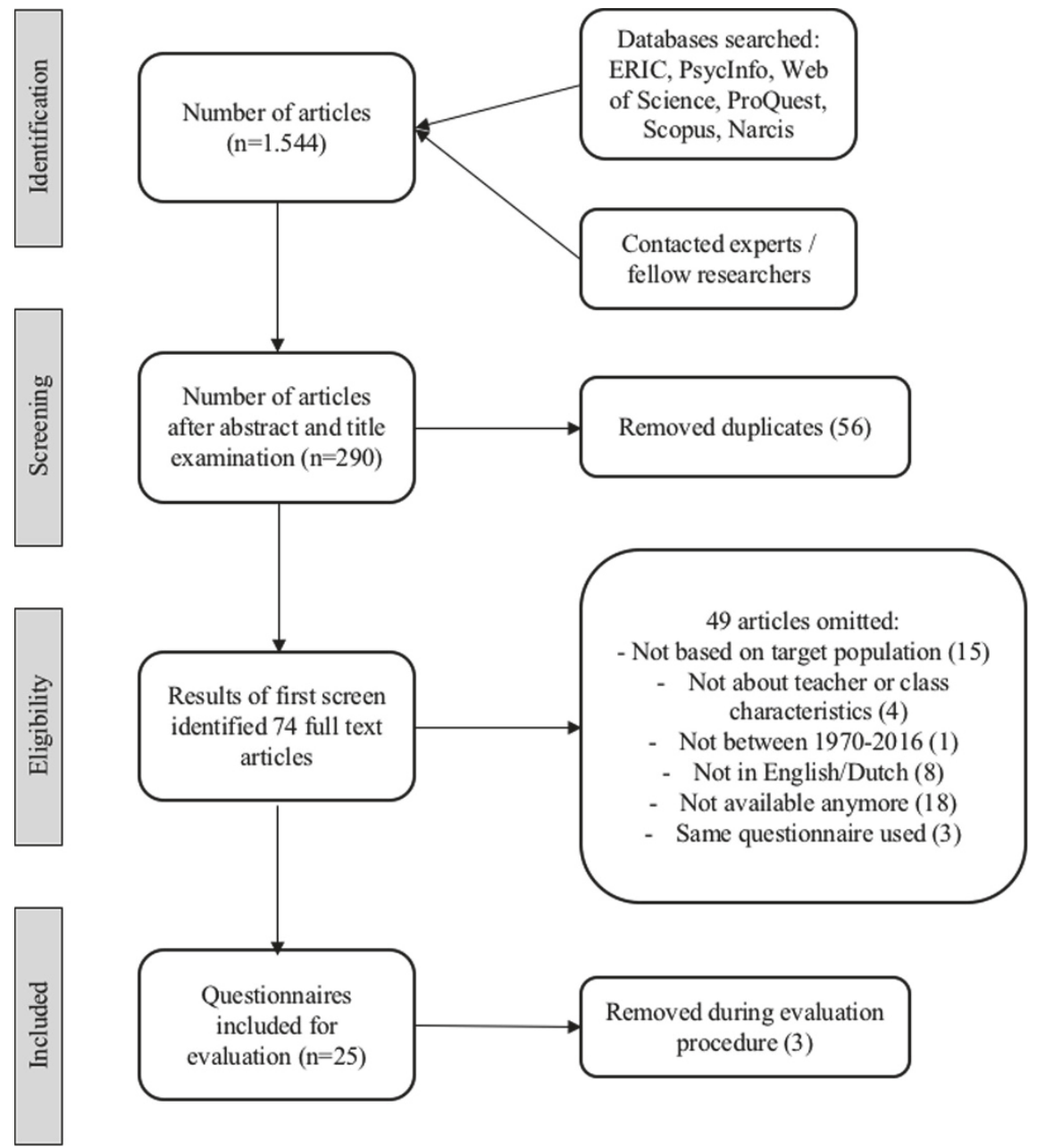

Fig. 1 Flowchart of the PRISMA guidelines followed in this study

\subsection{Evaluation Framework}

The evaluation framework consists of seven evaluation standards (as described earlier in this chapter) with 26 questions about the quality of the SPQ (ranging from 3 to 5 questions per standards). The reviewers scored all questions on a dichotomous scale (met or not met). The reviewers were instructed to assign the score "not met" if there was not enough evidence to evaluate a standard. The reviewers were required to give a reason for every response. 


\subsection{Analysis}

The results of this review are descriptively consisting of description of the SPQs based on information about the SPQs and the evaluation framework, descriptive statistics from the results of the review based on the evaluation standards in the evaluation framework, and, if relevant, description of the reasons for a score. These reasons were analyzed qualitatively by open and axial coding.

\section{Results}

\subsection{General Information}

An overview of the 22 questionnaires can be found in Table 1. The number of items differed, ranging from 16 to 96 . Eleven questionnaires used a 5-point rating scale, seven questionnaires a 4-point rating scale; one questionnaire a 3-point rating scale, two questionnaires a 2-point rating scale, and one questionnaire used both a 3 and a 5-point rating scale. Fifteen questionnaires were developed for secondary education, four for primary education, and three could be used for both (according to the authors of the questionnaire). Questionnaires differed in their date of development. Eleven questionnaires were developed between 2005 and 2014, five between 1995 and 2004, three questionnaires between 1985 and 1994, and the oldest three between 1970 and 1994. SPQ assessment purposes differed across the questionnaires. All SPQs were intended for research practices, while some were additionally used as a feedback tool (5) or for measurement purposes (4). Only two SPQs were developed to make an evidentiary argument (2). Remarkable, criterion validity could be evaluated in SPQs that were intended for measurement assessment (e.g., intended to specify and test assessment models as a way to work toward models that enable representation of realworld resources). All SPQs measured at least one of the teaching quality constructs described earlier (a safe and stimulating classroom climate, classroom management, the involvement and motivation of students, explanation of subject matter, the quality of subject-matter representation, cognitive activation, assessment for learning, differentiated instruction, and teaching learning strategies and student self-regulation). See Table 2 for an overview of the teaching quality constructs measured by the SPQs.

\subsection{Evaluation Results}

The evaluation results can be found in Table 1. Regarding the theoretical basis of the questionnaire as specified in the evaluation framework (standard one), all SPQs met the evaluation standard. This means that the constructs could be derived from different theories, researches, or standards, but all had a solid scientific basis and the 


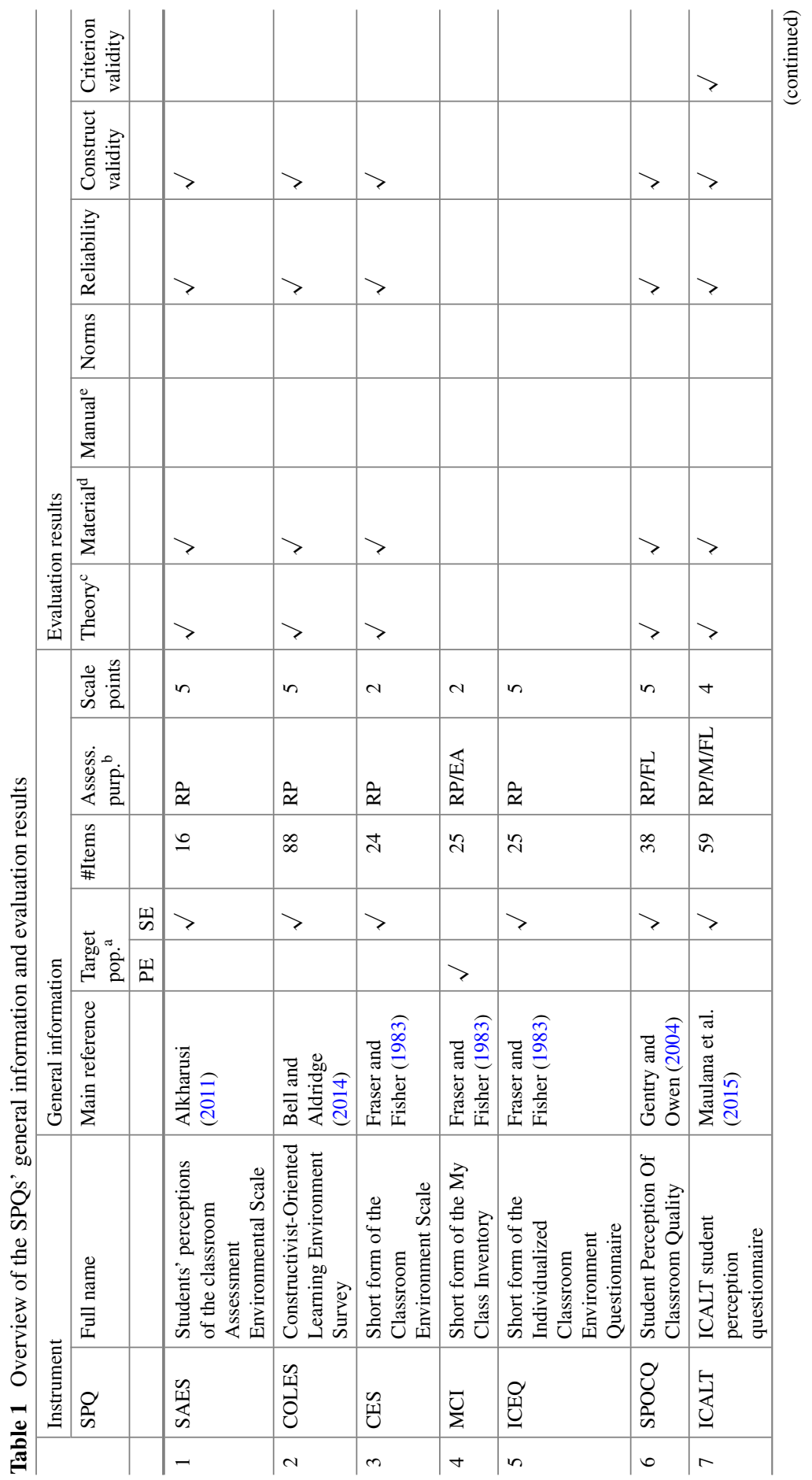




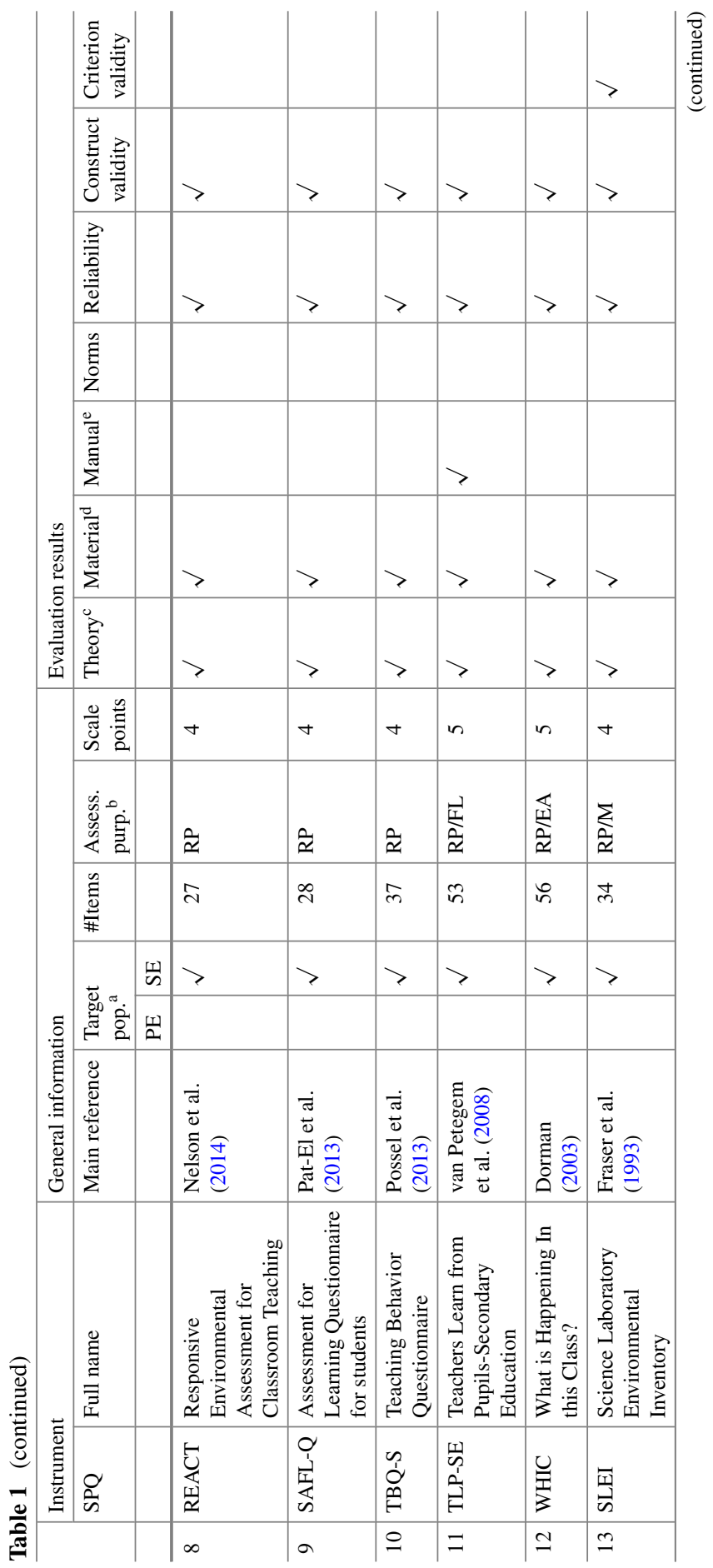




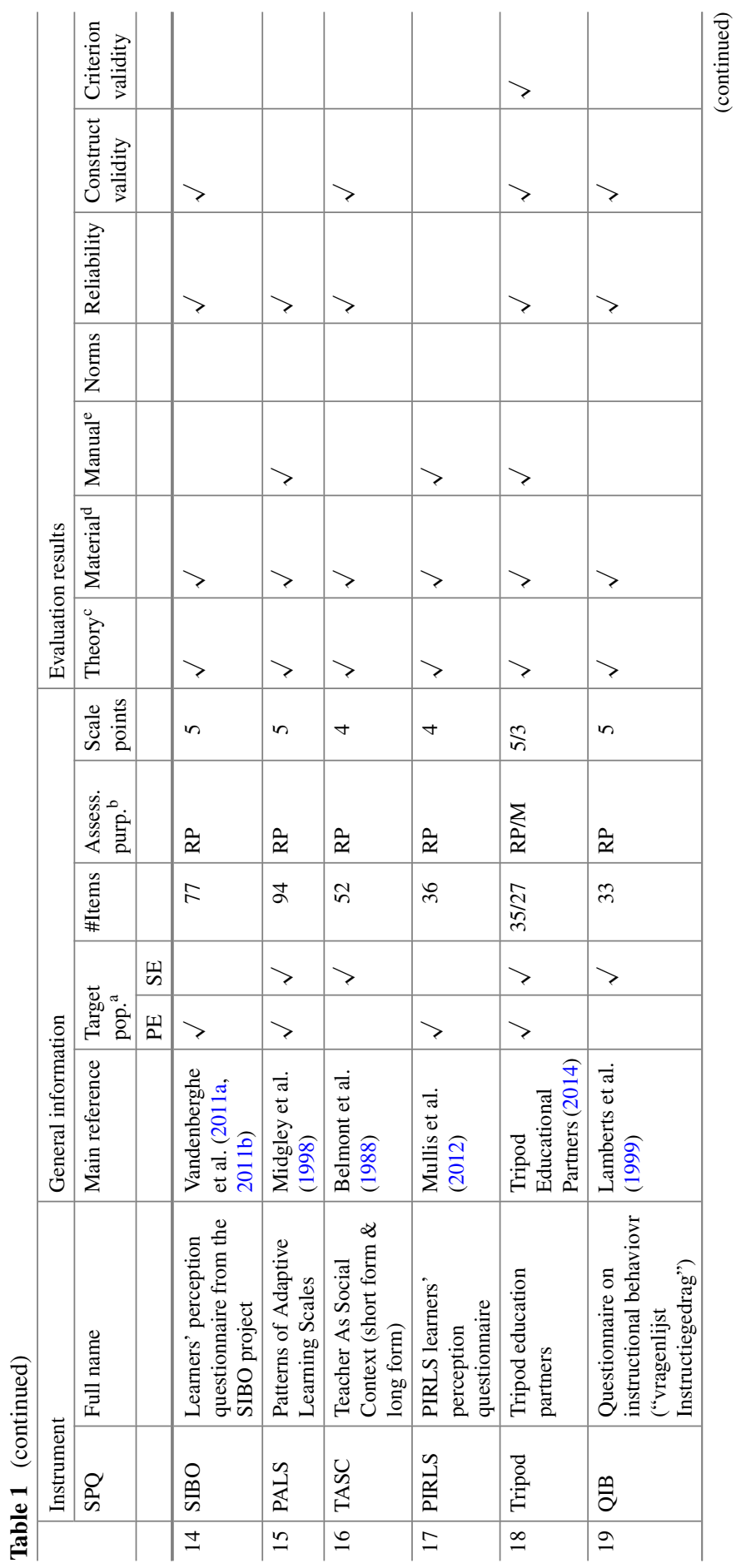




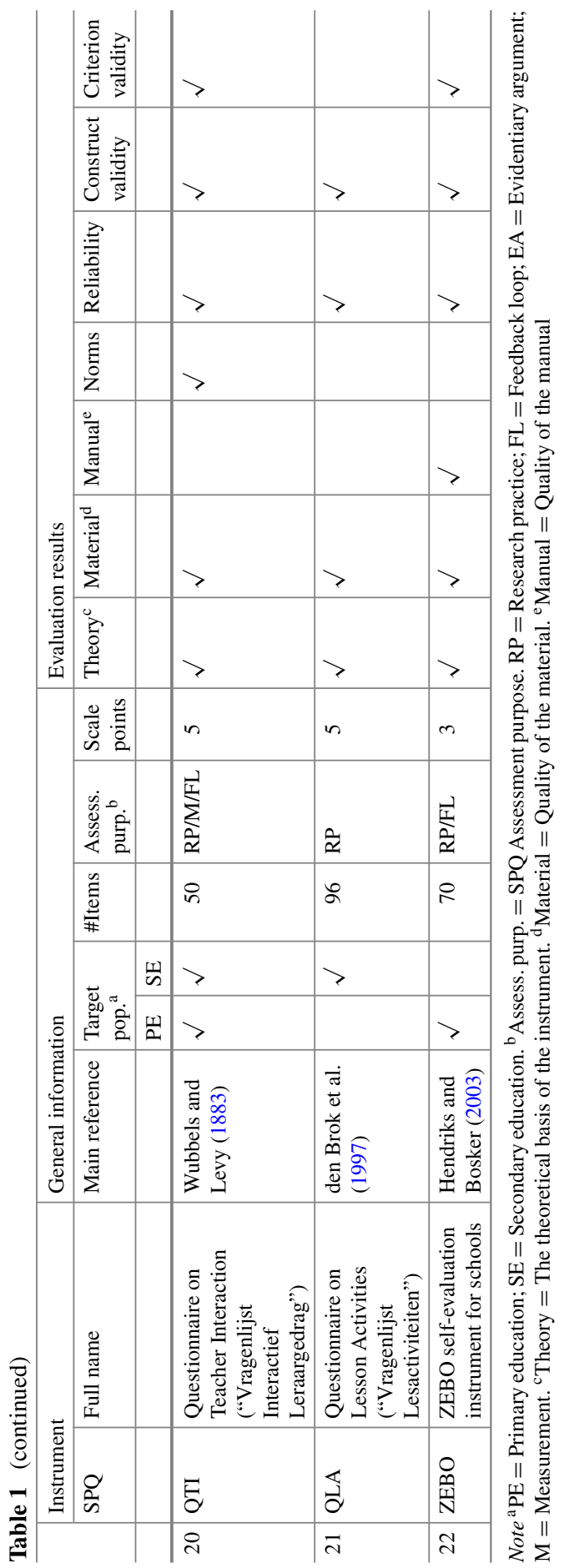


4 The Quality of Student Perception Questionnaires ...

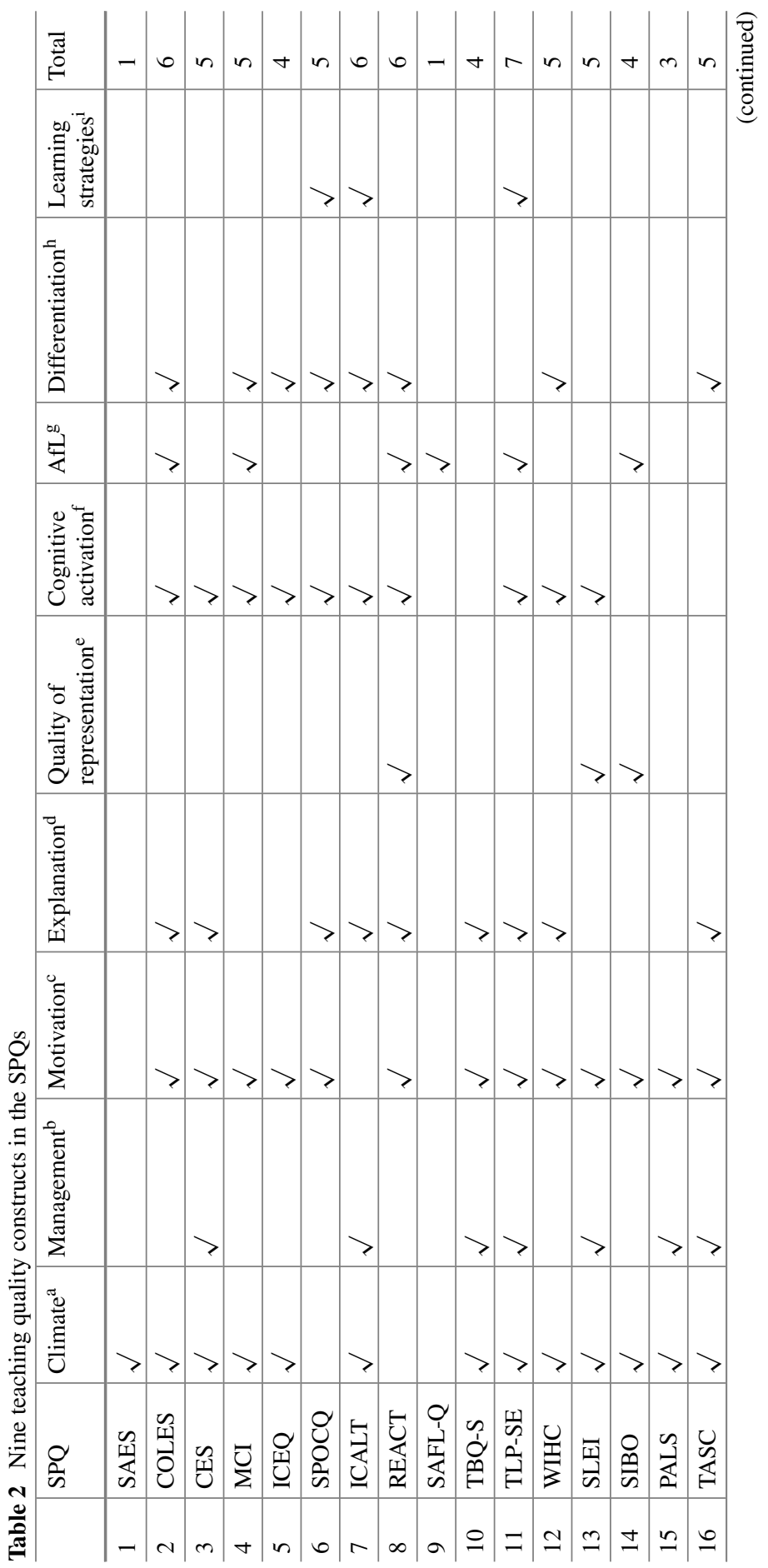




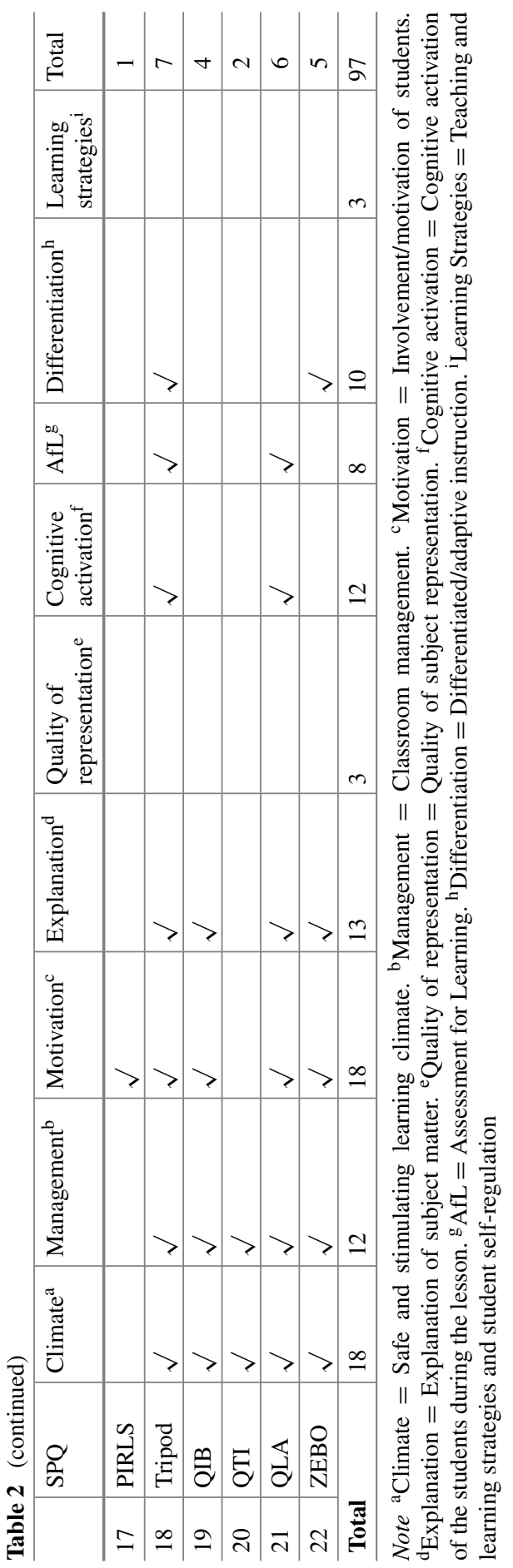


items covered the theoretical constructs. Although the theoretical basis of the SPQs was evaluated in this review, it was not feasible to evaluate the quality of the research underlying the questionnaire, as well. Constructs also differed across SPQs in the way they were operationalized in items.

Standard two of the evaluation framework (the quality of the material) was met by $86 \%$ of the SPQs. A list of items (material) was useful for evaluation and two SPQs lacked such a list (except for items that were included in publications). Evaluation standard three considered the quality of the user guide. A user guide was available in five questionnaires, from which one out of the five was considered inadequate. Norms for the SPQ scores (standard four) were only given in two of the 22 SPQs. In one of the two cases in which the norms were given, norms were not satisfactory (ZEBO). Sample sizes were small and the research conducted on the norms was weak.

Regarding the psychometric quality of the SPQs (standard 5), for all but one SPQ, information about reliability was available and considered acceptable. A wide range of measurements was reported, for example, percentages of exact agreement between students, Cohen's kappa coefficient, or Cronbach's alpha correlation coefficient. The different measures of reliability are hard to compare because some imply absolute student score agreement while others imply student score consistency. For example, Fraser et al. (1993) reported the internal consistency using Cronbach's alpha (.70.95), while van Petegem et al. (2008) tested the split-half reliability of the results using the Spearman-Brown coefficient on the student level $\left(r_{s} .77-.90\right)$ and class level $\left(r_{s} .84-.95\right)$ and they presented the r-output of the Mokken scaling analyses as yet another measure of reliability. However, for most SPQs, an acceptable reliability coefficient was reported in at least one of the publications.

For all but two SPQs, information about construct validity (standard 6) was available provided by an exploratory or confirmatory factor analysis (EFA or CFA). Factor loadings on the teaching quality construct an SPQ aimed to measure were acceptable in all SPQs. Five SPQs reported measures of criterion validity (standard 7). For example, Tripod Educational Partners (2014) demonstrated the criterion validity of the 7Cs framework by examining the correlation between the 7Cs and other commonly used measures of teaching effectiveness. Another example is Maulana et al. (2015), who examined predictive validity by evaluating the link between the scores on the questionnaire and student self-report of academic engagement. The criterion validity was acceptable in these studies.

\section{Conclusion, Discussion, and Next Steps}

Generating valid and reliable measurements by means of a student perception questionnaire (SPQ) is not self-evident. However, as an overview of the SPQs that have been developed and of their quality has been lacking, users have been hampered in making deliberate choices with respect to which SPQ to use in their own context (for examples, see Chap. 8 by Wisniewski and Zierer, in this volume). From a scientific 
perspective, it is also valuable to evaluate the extent to which SPQs meet the general standards for measurement instruments. Therefore, this review gives an overview of SPQs that are available for measuring teaching quality in primary and secondary education. It provides information about the (psychometric) quality of the SPQs and about what constructs they measure. After conducting a systematic review, 22 SPQs were evaluated based on seven evaluation standards. The evaluation was conducted by two reviewers. After reviewing all SPQs separately, the reviewers came to a final judgment.

\subsection{What Was Learned}

The results of this study show that the reviewers were most positive about the theoretical basis of the SPQs and about the quality of the SPQ materials. For most SPQs, the reviewers were positive about the availability of empirical evidence regarding the reliability and validity of scores (except criterion validity). Moreover, the scoring tools in most SPQs were based on theory, research, and/or national standards. According to the reviewers, most SPQs also had acceptable reliability and construct validity. This could be partly explained by the well-known publication bias, in which only acceptable and confirmatory results get written about in order to increase the probability of publication (Falagas \& Vangelis, 2008).

However, norm information about the quality rating measures was often lacking and few sampling specifications were provided. Information about the features of the SPQs, if available, was often not presented in an accessible way by instrument developers (e.g., in a user manual) making it difficult for potential SPQ users to obtain an overview of the qualities of available SPQs and to decide which SPQs best fits their own context and intended use. This raises questions about the factors that may have caused this. For example:

- There might have been no perceived need to make the SPQ materials accessible to other users, as not all SPQs in this review were developed for use by third parties (for example, some were developed by researchers for use in their own research project) and/or instrument developers were not aware that their SPQ could be of use to others.

- The required resources, such as time and financing, might not have been available to develop materials for external users, to make SPQ materials accessible, and to keep the information on the SPQs updated.

- Questionnaire developers might not be aware of the information SPQ users need for proper SPQ use and/or to decide whether the SPQ is useful in their own context and for their own assessment purpose.

- Conventional standards for research into the qualities of SPQs might not be available. 


\subsection{Limitations of the Study}

It is important to note that the evaluation framework used in this study was based on the COTAN evaluation standards of Evers et al. (2010). These standards were developed for psychological tests in the social sciences and it is possible that the COTAN evaluation standards are not the best way to evaluate SPQs, although the conclusions drawn from the results would be similar in both cases.

Although a systematic search was conducted for all available SPQs, questionnaires could be missing from the final overview. Search terms were chosen, inclusion and exclusion criteria were formulated, and different search strings were used. Twentytwo questionnaires were found and evaluated in this review. With slightly different search strings, more or less extensive criteria, or with searching in different databases, other SPQs (e.g., in other languages) could have been found. This might also have to do with the timeframe during which the review was conducted. All information was gathered in 2016. Since multiple SPQs could still have been under development at that time, this review might not include all the information that is now available. However, there is no reason to believe that the conclusions of this review no longer apply.

\section{$5.3 \quad$ Next Steps}

In line with Dobbelaer (2019), who reviewed classroom observation systems, the creation of an international database with all SPQs, that have been developed, their materials and the research into them, could make SPQ developers more aware of the value of their SPQ for others. If SPQ materials are accessible to others, SPQs can also be researched and developed further (even if the instrument developers themselves did not have the resources to do so), which could also help to reduce the need to constantly develop new SPQs.

Furthermore, a standardized evaluation framework with quality standards and research standards for SPQs, designed to evaluate the quality of SPQs and the empirical evidence for the reliability and validity of SPQ scores, could make instrument developers more aware of the complexity of SPQ development and the research that is needed (for potential users). It could also make it easier for potential SPQ users to compare (the empirical evidence regarding) SPQs. Moreover, independent evaluations of the SPQs using a standardized evaluation framework can provide potential users with the information they need to make a well-informed choice of a SPQ as well as to examine the aims of the SPQs, the operationalization and definitions of the constructs being measured, the different ways to use them and to make sure the desired information will be obtained.

\section{Appendix: Search Terms}




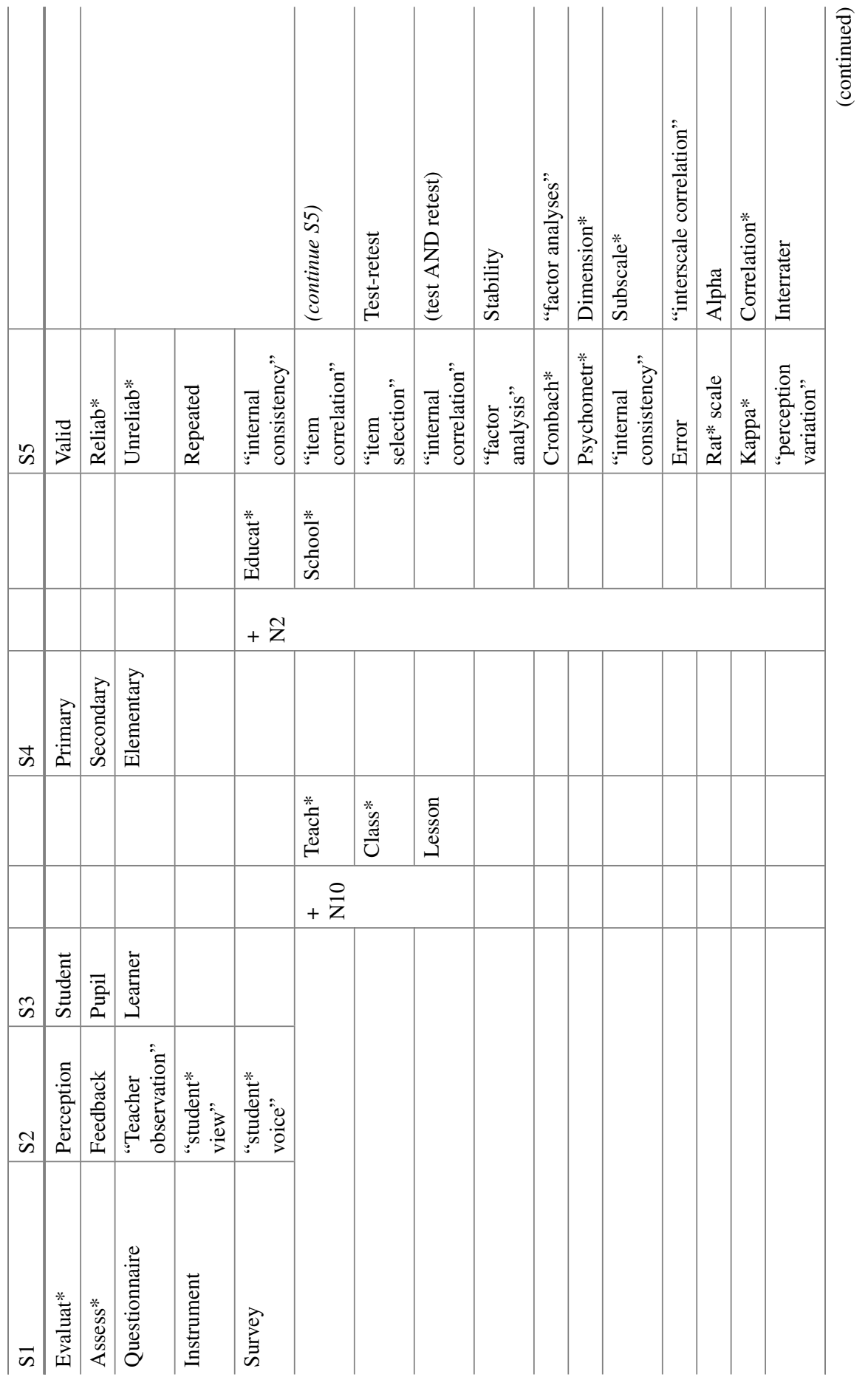




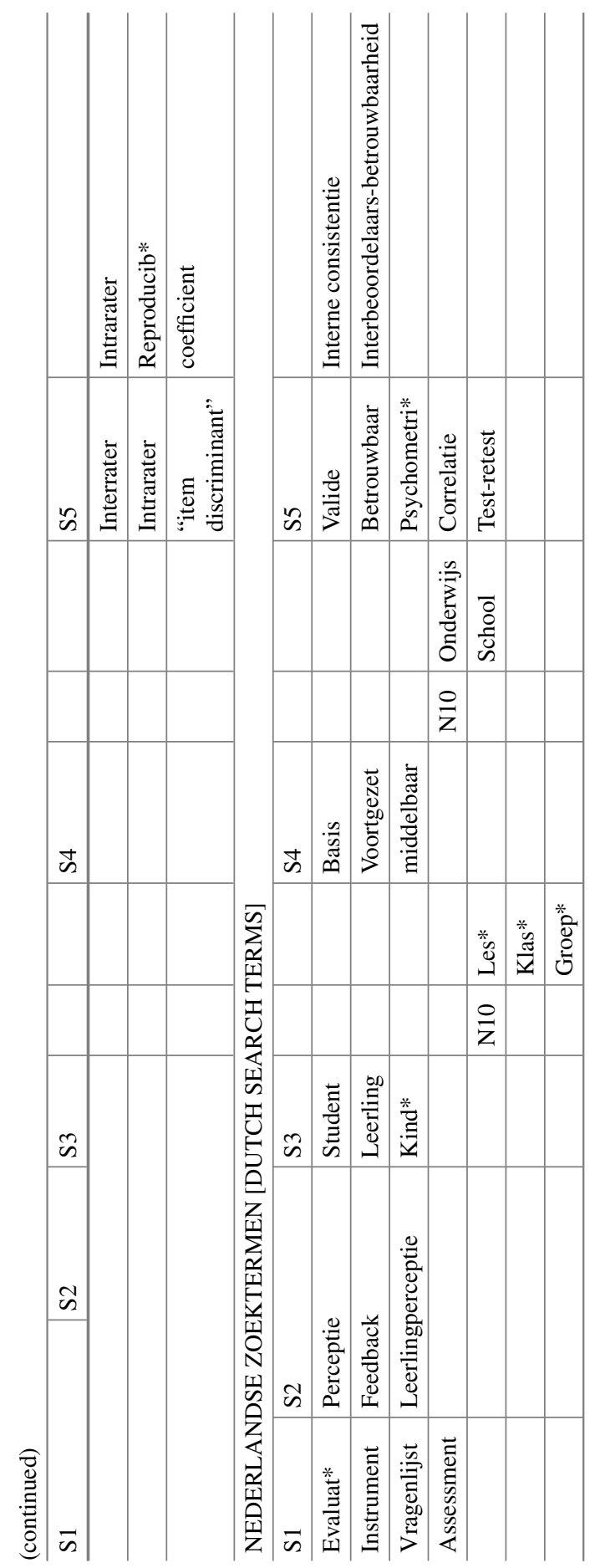




\section{References}

Alkharusi, H. (2011). Development and datametric properties of a scale measuring students' perceptions of the classroom assessment environment. International Journal of Instruction, 4, $105-120$.

American Educational Research Association (AERA), American Psychological Association (APA), and National Council on Measurement in Education (NCME). (1999). Standards for educational and psychological testing. American Educational Research Association.

Bechger, T., Hemker, B., \& Maris., G. (2009). Over het gebruik van continue normering [About the use of continuous standardization]. CITO.

Bell, C., \& Aldridge, J. M. (2014). Investigating the use of student perception data for teacher reflection and classroom improvement. Learning Environments Research, 17, 371-388.

Bell, C., Dobbelaer, M. J., Klette, K., \& Visscher, A. J. (2018). Qualities of classroom observation systems: School effectiveness and school improvement. https://www.tandfonline.com/doi/l1/10. 1080/09243453.2018.1539014?scroll=top\&needAccess=true. Accessed 6 Aug 2020.

Bell, C. A. (2019). What we see depends on how we look. QUINT Conference.

Belmont, M., Skinner, E., Wellborn, J., \& Connell, J. (1988). Teacher as social context: A measure of student perceptions of teacher provision of involvement, structure, and autonomy support (tech. rep. no. 102). University of Rochester.

Berk, R. A. (1986). A consumer's guide to setting performance standards on criterion-referenced tests. Review of Educational Research in Higher Education, 137-172.

Bijlsma, H. J. E., Glas, C., \& Visscher, A. J. (Under review). Are student perceptions reliable measures to evaluate teaching quality? Assessment.

Cohen, J., \& Goldhaber, D. (2016). Building a more complete understanding of teacher evaluation using classroom observations. Educational Researcher, 45, 378-387. https://doi.org/10.3102/001 3189 X16659442.

Creemers, B. M. P. (1994). The effective classroom. Cassall.

den Brok, P., Brekelmans, M., \& Wubbels, T. (1997). Vragenlijst lesactiviteiten. IVLOS.

Dobbelaer, M. J. (2019). The quality and qualities of classroom observation systems. Ipskamp Printing.

Dobbelaer, M. J., Visscher, A. J., \& Janssens, F. J. G. (2015, June). Review van lesobservatieinstrumenten [Review of classroom observation systems]. Onderwijs Research Dagen.

Dorman, J. P. (2003). Cross-national validation of the what is happening in this class? (WIHIC) questionnaire using confirmatory factor analysis. Learning Environment Research, 6, 231-245. https://doi.org/10.1023/A:1027355123577.

Drenth, P. J. D., \& Sijtsma, K. (2006). Testtheorie [Test theory]. Bohn Stafleu van Loghum.

Evers, A., Lucassen, W., Meijer, R., \& Sijtsma, K. (2010). COTAN beoordelingssysteem voor de kwaliteit van tests [COTAN evaluation system for the evaluation of test quality]. Heijnis \& Schipper.

Falagas, M. E., \& Vangelis, G. A. (2008). The top-ten in journal impact factor manipulation. Archivum Immunologiae et Therapiae Experimentalis, 56, 223-226. https://doi.org/10.1007/s00 005-008-0024-5.

Ferguson, R. (2012). Can student surveys measure teaching quality? Phi Delta Kappan, 94, 24-28. https://doi.org/10.1177/003172171209400306.

Ferguson, R., \& Danielson, C. (2014). How framework for teaching and Tripod 7Cs evidence distinguish key components of effective teaching. In T. J. Kane, K. A. Kerr, \& R. C. Pianta (Eds.), Designing teacher evaluation systems. Jossey-Bass.

Fraser, B. J., \& Fisher, D. L. (1983). Development and validation of short forms of some instruments, measuring student perceptions of actual and preferred classroom learning environment. Science Education, 67, 115-131.

Fraser, B. J., McRobbie, C. J., \& Giddings, G. J. (1993). Development and cross-national validation of a laboratory classroom environment instrument for senior high school science. Science Education Assessment Instruments, 77, 1-24. 
Gentry, M., \& Owen, S. V. (2004). Secondary student perceptions of classroom quality: Instrumentation and differences between advanced/honors and non-honors classes. Journal of Secondary Gifted Education, 16, 20-29.

Guttman, L. (1945). A basis for analyzing test-retest reliability. Psychometrika, 10, 255-282.

Hendriks, M., \& Bosker, R. J. (2003). ZEBO: Instrument voor zelfevaluatie in het basisonderwijs [ZEBO: instrument for self-evaluation in primary education]. Twente University Press.

Kane, M. T. (2006). Validation. In R. L. Brennan (Ed.), Educational measurement. American Council on Education and Praeger Publishers.

Lamberts, R., Den Brok, P., Derksen, K., \& Bergen, T. (1999). Het concept activerende instructie gemeten via perceptie van leerlingen [The concept of activating instruction measured through student perceptions]. Pedagogische studiën, 76, 36-50.

Liberati, A., Altman, D. G., Tetzlaff, J., Murrow, C., Gøtzsche, P. C., Ioannidis, J. P. A., \& Moher, D. (2009). The PRISMA statement for reporting systematic reviews and meta-analyses of studies that evaluate health care interventions: Explanation and elaboration. PLoS Med, 6, e1000100. https://doi.org/10.1371/journal.pmed.1000100.

Littell, J. H., Corcoran, J., \& Pillai, V. (2008). Systematic reviews and meta-analysis. Oxford University Press. https://doi.org/10.1177/1049731508318552.

Lüdtke, O., Trautwein, U., Kunter, M., \& Baumert, J. (2006). Reliability and agreement of student ratings of the classroom environment: A reanalysis of TIMSS data. Learning Environments Research, 9, 215-230. https://doi.org/10.1007/s10984-006-9014-8.

Marsh, H. D. (2007). Students' evaluations of university teaching: Dimensionality, reliability, validity, potential biases and usefulness. In R. P. Perry \& J. C. Smart (Eds.), The scholarship of teaching and learning in higher education: An evidence-based perspective. Springer. https:// doi.org/10.1007/1-4020-5742-3_9.

Marzano, R. J. (2012). The two purposes of teacher evaluation. Educational Leadership, 70, 14-19.

Maulana, R., \& Helms-Lorenz, M. (2016). Observations and student perceptions of the quality of preservice teachers' teaching behaviour: Construct representation and predictive quality. Learning Environments Research, 19, 335-357.

Maulana, R., Helms-Lorenz, M., \& van de Grift, W. (2015). Development and evaluation of a questionnaire measuring pre-service teachers' teaching behaviour: A Rasch modelling approach. School Effectiveness and School Improvement, 26, 169-194.

Midgley, C., Kaplan, A., Middleton, M., Urdan, T., Maehr, M. L., Hicks, L., \& Roeser, R. W. (1998). Development and validation of scales assessing students' achievement goal orientation. Contemporary Educational Psychology, 23, 113-131.

Mislevy, R. J. (2013). Four metaphors we need to understand assessment: Report of The Gordon Commission on the future of assessment in education. Educational Testing Service.

Moher, D., Liberati, A., Etzlaff, J., \& Altman, D. G. (2009). Preferred reporting items for systematic reviews and meta-analyses: The PRISMA statement. PLoS Med, 6 .

Mullis, I. V. S., Martin, M. O., Foy, P., \& Drucker, K. T. (2012). PIRLS 2011 international reading results. TIMSS \& PIRLS International Study Center.

Nelson, P. M., Demers, J. A., \& Christ, T. J. (2014). The responsive environmental assessment for classroom teaching (REACT): The dimensionality of student perceptions of the instructional environment. School Psychology Quarterly, 29, 182-197. https://doi.org/10.1037/spq0000049.

Nunnally, J. C. (1967). Psychometric theory. McGrawhill.

Pat-El, R., Jonathan, R. J., Tillema, H., Segers, M., \& Vedder, P. (2013). Validation of assessment for learning questionnaires for teachers and students. British Journal of Educational Psychology, 83, 98-113. https://doi.org/10.1111/j.2044-8279.2011.02057.x.

Pianta, R. C., \& Hamre, B. K. (2006). Conceptualization, measurement, and improvement of classroom processes: Standardized observation van leverage capacity. Educational Researcher, 38, 109-119. https://doi.org/10.3102/0013189X09332374.

Possel, P., Moritz-Rudasill, K., Adelson, J. L., Bjerg, A. C., Wooldridge, D. T., \& Black, S. W. (2013). Teaching behavior and well-being in students: Development and concurrent validity of 
an instrument to measure student-reported teaching behavior. International Journal of Emotional Education, 5, 5-30.

Praetorius, A. K., Klieme, E., Herbert, B., \& Pinger, P. (2018). Generic dimensions of teaching quality: The German framework of three basic dimensions. ZDM Mathematics Education, 50, 407-426.

Sammons, P., Hillman, J., \& Mortimore, P. (1995). Key characteristics of effective schools: A review of school effectiveness research. Institute of Education.

Schulz, J., Sud, G., \& Crowe, B. (2014). Lessons from the field: The role of student surveys in teacher evaluation and development. Bellwether Education Partners.

Strong, M. (2011). The highly qualified teacher: What is teacher quality and how do we measure it? Teachers College Press.

ten Berge, J. M. F., \& Socan, G. (2004). The greatest lower bound to the reliability of a test and the hypothesis of unidimensionality. Psychometrika, 69, 613-625. https://doi.org/10.1007/BF0228 9858.

Timperley, H., Wilson, A., Barrar, H., \& Fung, I. (2007). Teacher professional learning and development: Best evidence synthesis iteration. Ministery of Education.

Tripod Educational Partners U.K. (2014). Tripod's 7 cs. technical manual. Tripod Educational Partners.

van der Lans, R. M., \& Maulana, R. (2018). The use of secondary school student ratings of their teacher's skillfulness for low-stake assessment and high-stake evaluation. Studies in Educational Evaluation, 58, 112-121.

van der Scheer, E. A., Bijlsma, H. J. E., \& Glas, C. (2018). Validity and reliability of student perceptions of teaching quality in primary education. School Effectiveness and School Improvement.

van Petegem, P., Deneire, A., \& de Maeyer, S. (2008). Evaluation and participation in secondary education: Designing and validating a self-evaluation instrument for teachers to solicit feedback from pupils. Studies in Educational Evaluation, 34, 136-144. https://doi.org/10.1016/j.stueduc. 2008.07.002.

Vandenberghe, N., Cortois, L., De Bilde, V., Verschueren, K. \& van Damme, J. (2011a). Longitidunaal onderzoek in het basisonderwijs. Leerlingperceptie vragenlijst in het zesde leerjaar [Longitidunal research in primary education: Student perception questionnaire in the fourth grade]. Steunpunt SSL.

Vandenberghe, N., Cortois, L., De Bilde, V., Verschueren, K., \& van Damme, J. (2011b). Longitidunaal onderzoek in het basisonderwijs. Leerlingvragenlijst einde basisonderwijs [Longitidunal research in primary education: Student perception questionnaire for sixth grade]. Steunpunt SSL.

Vos, H. J., \& Knuver, J. W. M. (2000). Standaarden in onderwijsevaluatie [Standards in educational evaluation]. In R. J. Bosker (Ed.), Onderwijskundig lexicon (Editie III), Evalueren in het onderwijs [Educational lexicon (Edition III), Evaluation in education]. Samsom.

Wallace, T., Kelcey, B., \& Ruzek, E. (2016). What can student perception surveys tell us about teaching. American Educational Research Journal, 53(6), 1834-1868. https://doi.org/10.3102/ 0002831216671864. 
Wubbels, T., \& Levy, J. (1883). Do you know what you look like? Interpersonal relationships in education. The Falmer Press.

Hannah Bijlsma is a researcher (Ph.D.) at the section of Teacher Professionalization at the University of Twente (The Netherlands) and as a primary school teacher (grade 1). Her research focuses on measuring teaching quality and on the use of student perceptions of teaching quality in school contexts. In 2016 she founded a professional association for academic primary school teachers, of which she has been chairman for about five years. She is now a board member of the International Congress for School Effectiveness and Improvement (ICSEI) and a board member of the EARLI SIG on School Effectiveness and Improvement.

Open Access This chapter is licensed under the terms of the Creative Commons Attribution 4.0 International License (http://creativecommons.org/licenses/by/4.0/), which permits use, sharing, adaptation, distribution and reproduction in any medium or format, as long as you give appropriate credit to the original author(s) and the source, provide a link to the Creative Commons license and indicate if changes were made.

The images or other third party material in this chapter are included in the chapter's Creative Commons license, unless indicated otherwise in a credit line to the material. If material is not included in the chapter's Creative Commons license and your intended use is not permitted by statutory regulation or exceeds the permitted use, you will need to obtain permission directly from the copyright holder. 